\title{
RESEARCH
}

Open Access

\section{Biological characterization of compounds from Rhinella schneideri poison that act on the complement system}

Fernando A. P. Anjolette ${ }^{1}$, Flávia P. Leite , Karla C. F. Bordon', Ana Elisa C. S. Azzolini', Juliana C. Pereira², Luciana S. Pereira-Crott ${ }^{2}$ and Eliane C. Arantes ${ }^{1 *}$

\begin{abstract}
Background: The skin secretions of toads of the family Bufonidae contain biogenic amines, alkaloids, steroids (bufotoxins), bufodienolides (bufogenin), peptides and proteins. The poison of Rhinella schneideri, formerly classified as Bufo paracnemis, presents components that act on different biological systems, including the complement system. The aim of this study was to isolate and examine the activity of Rhinella schneideri poison (RsP) components on the complement system.
\end{abstract}

Methods: The components active on the complement system were purified in three chromatographic steps, using a combination of cation-exchange, anion-exchange and gel filtration chromatography. The resulting fractions were analyzed by SDS-PAGE and screened for their activity in the hemolytic assay of the classical/lectin complement pathways. Fractions active on the complement system were also assessed for their ability to generate C3 fragments evaluated by two dimensional immunoelectrophoresis assay, C3a and C5a by neutrophil chemotaxis assay and SC5b-9 complex by ELISA assay.

Results: The fractionation protocol was able to isolate the component $\mathrm{S} 5$ from the RsP, as demonstrated by SDS-PAGE and the RP-FPLC profile. S5 is a protein of about $6000 \mathrm{Da}$, while S2 presents components of higher molecular mass $(40,000$ to $50,000 \mathrm{Da})$. Fractions S2 and S5 attenuated the hemolytic activity of the classical/lectin pathways after preincubation with normal human serum. Both components stimulated complement-dependent neutrophil chemotaxis and the production of C3 fragments, as shown by two-dimensional immunoelectrophoresis. S2 showed a higher capacity to generate the SC5b-9 complex than the other fractions. This action was observed after the exposure of normal human serum to the fractions.

Conclusions: This is the first study to examine the activity of RsP components on the complement system. Fractions S2 and S5 reduced the complement hemolytic activity, stimulated complement-dependent neutrophil chemotaxis and stimulated the production of C3 fragments, indicating that they were able to activate the complement cascade. Furthermore, fraction S2 was also able to generate the SC5b-9 complex. These components may be useful tools for studying dysfunction of the complement cascade.

Keywords: Complement system, Hemolytic activity, Neutrophil chemotaxis, Rhinella schneideri, Terminal complement complex (SC5b-9), Toad poison

\footnotetext{
* Correspondence: ecabraga@fcfrp.usp.br

'Department of Physics and Chemistry, School of Pharmaceutical Sciences of Ribeirão Preto, University of São Paulo (USP), Avenida do Café, s/n, Ribeirão Preto 14.040-903 SP, Brazil

Full list of author information is available at the end of the article
}

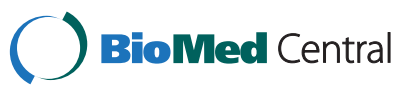

(c) 2015 Anjolette et al. This is an Open Access article distributed under the terms of the Creative Commons Attribution License (http://creativecommons.org/licenses/by/4.0), which permits unrestricted use, distribution, and reproduction in any medium, provided the original work is properly credited. The Creative Commons Public Domain Dedication waiver (http:// creativecommons.org/publicdomain/zero/1.0/) applies to the data made available in this article, unless otherwise stated. 


\section{Background}

The family Bufonidae, with more than 590 species distributed among 50 genera, is one of the largest Anuran families [1]. The genus Rhinella is composed of 88 species, of which 36 are found in Brazil [1]. Rhinella schneideri, previously known as Bufo paracnemis, is the species most commonly encountered in Brazil [2, 3].

Amphibian skin secretions contain a large number of biologically active compounds that are involved in the regulation of physiological functions of the skin, as well as in defense mechanisms against predators and microorganisms [4]. The skin glands produce mucus, peptides, biogenic amines, steroids, and alkaloids. Pharmacologically, these substances may be neurotoxic, cardiotoxic, hemotoxic or myotoxic, and can provoke anesthetic, hypotensive and/or hypertensive effects $[5,6]$.

Dried poison from the skin glands of the Chinese toad (Bufo bufo gargarizans cantor) has been used as a therapeutic agent in traditional Chinese medicine, as well as in other Asian countries [7-9]. Isolated components from toad glands have been used to treat several types of cancer [10-15]. A previous report described the influence of Rhinella schneideri poison $(R s \mathrm{P})$ on the lytic activity of the complement system [16].

The complement system (CS) is one of the main defense mechanisms of vertebrates and encompasses over 30 proteins, some of which circulate in the plasma as precursors. Depending on the stimulus, complement activation occurs by classical, alternative or lectin pathways (CP, AP and LP, respectively), leading to a cascade of component interactions and the generation of products that can exert biological activities such as anaphylaxis, chemotaxis, opsonization, immune complex solubilization and participation in the immune response. After recognition, a series of serine proteases is activated, culminating in formation of the "membrane attack complex" (MAC) within the membrane that leads to lysis or cell activation. Two important mediators of the inflammatory reaction, C3a and C5a, are produced as a consequence of CS activation. However, inappropriate activation can result in substantial injury. To prevent undesired complement activation, inhibitors acting at different stages of the activation pathways are used. Despite the large number of inhibitory compounds identified so far, there is still a need for selective complement system modulators [17-19].

Since the poisonous secretion of the parotoid gland of the $R$. schneideri toad presents anticomplement activity, this work aimed to purify the active components and to investigate their effects on the complement system [16].

\section{Methods}

\section{Poison}

The poison was collected by applying pressure to parotoid glands of Rhinella schneideri toads, immediately desiccated under vacuum and stored at $-20{ }^{\circ} \mathrm{C}$ until usage. Prior to the assays, the poison or toxin solutions were filtered through sterilizing membranes (Merck-Millipore, Germany cellulose ester filters: $0.45 \mu \mathrm{m}$ and $0.22 \mu \mathrm{m}$, respectively).

\section{Experimental animals}

An adult male sheep from the animal facility of the University of São Paulo in Ribeirão Preto was kept in accordance with the ethical guidelines established by the Brazilian College of Animal Experimentation (COBEA). All experiments were approved and conducted in accordance with the ethical principles in animal experimentation adopted by the Ethics Commission for the Use of Animals (CEUA), Campus of Ribeirão Preto, USP (protocol $n^{\circ}$ 05.1.637.53.6).

\section{Fractionation of $R$. schneideri poison}

The soluble material from the desiccated poison (500 mg) was clarified by filtration through membranes (0.45 $\mu \mathrm{m}$ and then $0.22 \mu \mathrm{m}$, Merck-Millipore, Germany). The material was chromatographed at $4{ }^{\circ} \mathrm{C}$ on a $2.5 \times$ $63.0 \mathrm{~cm}$ column of CM-cellulose-52 (Whatman, USA), which was equilibrated and initially eluted with $300 \mathrm{~mL}$ of $0.05 \mathrm{M} \mathrm{NH}_{4} \mathrm{HCO}_{3}$ buffer, $\mathrm{pH} 7.8$, when a convex concentration gradient was started from 0.05 to $1.00 \mathrm{M}$ $\mathrm{NH}_{4} \mathrm{HCO}_{3}$ buffer. Fractions of $3.0 \mathrm{~mL}$ were collected. Absorbance at $280 \mathrm{~nm}$ and buffer concentration profiles were then traced as previously described [20].

The resulting pools, designated $\mathrm{C} 1$ to $\mathrm{C} 7$, were then lyophilized until salt-free. The fraction $\mathrm{C} 1$ showed the lowest percentage of hemolysis. Therefore, C1 was submitted to the next fractionation step. The soluble material from fraction $\mathrm{C} 1(56.6 \mathrm{mg}$ in $5 \mathrm{~mL}$ of $0.05 \mathrm{M}$ Tris$\mathrm{HCl}$, pH 7.8, centrifuged at $15,700 \times g$, at $4{ }^{\circ} \mathrm{C}$, for $10 \mathrm{~min}$ ) was applied on a $1.0 \times 10.0 \mathrm{~cm}$ DEAE-Sepharose column at room temperature, previously equilibrated with $0.05 \mathrm{M}$ Tris- $\mathrm{HCl}, \mathrm{pH} 7.8$ (buffer A). Elution was performed with a linear gradient of buffer B (0.05 M Tris- $\mathrm{HCl}$ supplemented with $1.0 \mathrm{M} \mathrm{NaCl}, \mathrm{pH} 7.8$ ), at a flow rate of $0.5 \mathrm{~mL} / \mathrm{min}$. Absorbance was monitored at $280 \mathrm{~nm}$. The chromatography was performed in an Äkta ${ }^{\mathrm{Tm}}$ Prime system (GE Healthcare, Sweden) and the resulting pools, denominated D1 to D4, were lyophilized. Fraction D3 showed the highest activity on the complement system and was submitted to a molecular filtration on a Sephacryl S-200 column $(1.6 \mathrm{~cm} \times 60 \mathrm{~cm})$ at room temperature, previously equilibrated with PBS (phosphate buffered saline), $\mathrm{pH} 7.4$, at a flow rate of $0.4 \mathrm{~mL} /$ min. The absorbance was monitored at $254 \mathrm{~nm}$. The resulting pools, designated S1 to S5 were grouped according to their respective absorbance peaks and stored at $-20{ }^{\circ} \mathrm{C}$.

Fractions S2 and S5, which showed activity on the complement system, were submitted to a reversed phase 
FPLC using a C2C18 column $(0.46 \times 10 \mathrm{~cm}$, Amersham Biosciences, Sweden). The column was equilibrated with $0.1 \%(\mathrm{~V} / \mathrm{V})$ trifluoroacetic acid (TFA, solution A); and the components were eluted by a step concentration gradient from 0 to $100 \%$ of solution B (80\% acetonitrile, $0.1 \%$ trifluoroacetic acid, $\mathrm{V} / \mathrm{V}$ ), at a flow rate of $0.5 \mathrm{~mL} / \mathrm{min}$, at room temperature. The absorbance $(\lambda=214 \mathrm{~nm})$ was registered by the Äkta ${ }^{\mathrm{max}}$ Prime system (GE Healthcare, Sweden).

\section{Polyacrylamide gel electrophoresis}

Sodium dodecyl sulfate polyacrylamide gel electrophoresis (SDS-PAGE) was run as described by Laemmli [21]. The gel was stained with Silver Staining Kit Protein (Pharmacia Biotech, Sweden) or Coomassie Blue R-350. Conditions of voltage and amperage (maximum values: $90 \mathrm{~V}, 40 \mathrm{~mA}$ and $15 \mathrm{~W}$ ) were controlled by an EPS 3500 XL Electrophoresis Power Supply (Pharmacia Biotech, Sweden).

\section{Solutions}

Cells were washed in PBS, pH 7.4, and complement fixation diluent (CFD) containing $0.1 \%$ gelatin (gel) was used for hemolytic assays of CP/LP activity as described by Harrison and Lachmann [22]. Modified Alsever's solution [23] was used as an anticoagulant for sheep blood storage.

\section{Normal human serum (NHS) and erythrocytes}

Human blood was obtained from healthy donors (approval certificate by the Research Ethics Committee - CAAE, protocol $\mathrm{n}^{\circ}$ 0022.0.212.000-08). Blood samples were collected from healthy volunteers of both sexes (aged 20 to 30 years) without anticoagulant and allowed to clot for one hour at room temperature, after which they were centrifuged at $556 \times g$, for ten minutes at $4{ }^{\circ} \mathrm{C}$, and the NHS obtained was stored at $-70{ }^{\circ} \mathrm{C}$.

Healthy adult male sheep were bled by jugular vein puncture; the blood was collected in two volumes of Alsever's modified solution, stored at $4{ }^{\circ} \mathrm{C}$ and utilized for 15 days as a source of erythrocytes for CP/LP hemolytic assays. Sheep blood was centrifuged $(556 \times g, 15 \mathrm{~min}$, $4{ }^{\circ} \mathrm{C}$ ), after which the plasma and buffy coat were discarded. Red cells were washed twice in PBS, suspended in CFD/Gel and mixed with an appropriate volume of antisheep erythrocyte antibody. This erythrocyte-antibody suspension was maintained at $4{ }^{\circ} \mathrm{C}$ for $15 \mathrm{~min}$ and its absorbance at $700 \mathrm{~nm}$ was adjusted to $0.70-0.80$.

\section{Hemolytic complement assay}

NHS was diluted in CFD/Gel at a ratio of $1: 20, \mathrm{~V} / \mathrm{V}$. Fractions $\left(100 \mu \mathrm{L}\right.$ in PBS, $\mathrm{S} 1-\mathrm{A}_{280} \sim 0.35$; $\mathrm{S} 2-\mathrm{A}_{280} \sim$ 0.20; $\mathrm{S} 3-\mathrm{A}_{280} \sim 0.17$; $54-\mathrm{A}_{280} \sim 0.10$ and $\mathrm{S} 5-\mathrm{A}_{280} \sim$ 0.16) obtained from D3 molecular filtration (Sephacryl S-200) were incubated with CFD/Gel solution $(12.5 \mu \mathrm{L})$ and diluted serum $(1: 20 ; 37.5 \mu \mathrm{L})$ for one hour at $37^{\circ} \mathrm{C}$. After the incubation period, erythrocyte-antibody suspension $(100 \mu \mathrm{L})$ was added to the samples and a new incubation was performed for $30 \mathrm{~min}$ at $37{ }^{\circ} \mathrm{C}$. At the end of the incubation, cold PBS $(250 \mu \mathrm{L})$ was added to the samples, which were then centrifuged at $556 \times g$ for ten minutes. The percentage of lysis was determined by the absorbance at $412 \mathrm{~nm}$, using as $100 \%$ lysis control the suspension of lysed erythrocytes in water, and as $0 \%$ lysis control the cells incubated in CFD/Gel. The positive control was prepared under the same reaction conditions except that the fraction volume was replaced by PBS $(100 \mu \mathrm{L})$. This assay was employed to monitor the activity of the fractions on the complement system during the purification process.

\section{Human neutrophils suspension}

Human blood from healthy donors was mixed with modified Alsever's solution (V/V) and centrifuged at $978 \times g$ for ten minutes. Neutrophils were isolated by the gelatin method, as described by Paula et al. [24] with modifications. Briefly, after blood centrifugation, the plasma and buffy coat were discarded, and the cell pellet was suspended in two volumes of $2.5 \%$ gelatin solution prepared in $0.15 \mathrm{M} \mathrm{NaCl}$. This suspension was incubated for $15 \mathrm{~min}$ at $37{ }^{\circ} \mathrm{C}$. After incubation, the upper neutrophil-rich layer was collected, diluted in $30 \mathrm{~mL}$ of $0.15 \mathrm{M} \mathrm{NaCl}$ solution and centrifuged at $757 \times g$ for ten minutes at room temperature. The cell pellet was sus-

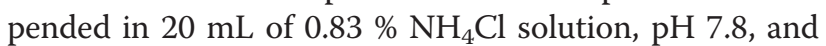
incubated for five minutes at $37{ }^{\circ} \mathrm{C}$, in order to lyse remaining erythrocytes. After incubation, the supernatant was discarded and the suspension was centrifuged at $757 \times g$ for ten minutes at room temperature. The cell pellet was washed in $30 \mathrm{~mL}$ of $0.15 \mathrm{NaCl}$ solution and centrifuged at $757 \times g$ for ten minutes. The supernatant was discarded and $1 \mathrm{~mL}$ of the neutrophil suspension was suspended in $1 \mathrm{~mL}$ of Hank's solution containing $0.1 \%$ gelatin. Cells were diluted (1:10) in Turk solution and counted in a Neubauer Chamber. The neutrophil purity of $80-90 \%$ with viability higher than $95 \%$ was accomplished by trypan blue exclusion test. One neutrophil suspension was standardized to contain $1.2 \times 10^{6}$ cells $\mathrm{mL}^{-1}$ and used in the neutrophil chemotaxis assay.

\section{Neutrophil chemotaxis assay}

The chemotaxis assay was performed using a modified version of Boyden's technique [25], in which $120 \mu \mathrm{L}$ of NHS with $50 \mu \mathrm{L}$ of $\mathrm{CFD} / \mathrm{Gel}$ and $50 \mu \mathrm{L}$ of each fraction, $\mathrm{S} 1$ $\left(\mathrm{A}_{280} \sim 0.35\right), \mathrm{S} 2\left(\mathrm{~A}_{280} \sim 0.20\right), \mathrm{S} 3\left(\mathrm{~A}_{280} \sim 0.17\right), \mathrm{S} 4\left(\mathrm{~A}_{280} \sim\right.$ $0.10)$ and $\mathrm{S} 5\left(\mathrm{~A}_{280} \sim 0.16\right)$, obtained from molecular filtration of D3, were placed in the lower migration chamber and covered with a filter of $13 \mathrm{~mm}$ diameter and $3 \mu \mathrm{m}$ pore (SSWP 01300, Merck-Millipore, Germany). The upper 
compartment of the chamber was filled with $300 \mu \mathrm{L}$ of a suspension of human neutrophils $\left(1.2 \times 10^{6}\right.$ cells $\left.\mathrm{mL}^{-1}\right)$. Next, all chambers were closed and incubated at $37{ }^{\circ} \mathrm{C}$ for $60 \mathrm{~min}$ in a humid atmosphere. After incubation, the filters were removed from the chambers, fixed in propanol, stained with Harris hematoxylin, dehydrated in isopropanol and cleared with xylene. Each filter was placed between a slide and a coverslip with Entellan (Merck KGaA, Germany). A mixture of NHS $(120 \mu \mathrm{L})$ with CFD/Gel $(100 \mu \mathrm{L})$ and zymosan $(75 \mu \mathrm{L}, 1 \mathrm{mg} / \mathrm{mL})$ was used as positive control, and NHS $(120 \mu \mathrm{L})$ with CFD/Gel $(100 \mu \mathrm{L})$ as negative control.

Neutrophil migration within the filter was determined under light microscopy by the leading-front method, measuring in micrometers the greatest distance crossed by three cells per field [26]. At least ten fields were examined at $100 \times$ magnification for each filter.

\section{Two-dimensional immunoelectrophoresis (2D-IEP)}

For this analysis, $50 \mu \mathrm{L}$ of fractions $\mathrm{S} 2\left(\mathrm{~A}_{280} \sim 0.2\right)$ and $\mathrm{S} 5\left(\mathrm{~A}_{280} \sim 0.16\right)$ were preincubated in a water bath with $100 \mu \mathrm{L}$ of NHS $1: 2$ by $60 \mathrm{~min}$ at $37^{\circ} \mathrm{C}$. Immunoelectrophoresis was performed according to the method of Clark and Freeman [27], using glass plates $(5.5 \times 7.5 \times$ $0.2 \mathrm{~cm})$ and $1.3 \%$ agarose in buffer $(0.025 \mathrm{M}$ Tris- $\mathrm{HCl}$, $0.027 \mathrm{M}$ glycine, $0.02 \mathrm{M}$ sodium barbital, $0.01 \mathrm{M}$ EDTA, $\mathrm{pH}$ 8.8). In the first dimension, the positive control $(31.25 \mu \mathrm{L}$ of zymosan plus $100 \mu \mathrm{L}$ of $1: 2 \mathrm{NHS})$, the negative control (100 $\mu \mathrm{L}$ of $1: 2$ NHS plus $50 \mu \mathrm{L}$ of PBS) and fraction $\mathrm{S} 2$ and $\mathrm{S} 5(50 \mu \mathrm{L}$ of each fraction plus $100 \mu \mathrm{L}$ 1:2 NHS) were electrophoresed for four hours, at $140 \mathrm{~V}$ and $5 \mathrm{~mA} /$ plate. For the second dimension, the plates were completed with $1.3 \%$ agarose $(5 \mathrm{~mL})$ containing $1 \%$ anti-human C3 antibody (Calbiochem/ Merck, Germany) and electrophoresed for $14 \mathrm{~h}$, at $10 \mathrm{~W}$ and $5 \mathrm{~mA} /$ plate. The plates were dried at room temperature, stained with Ponceau $0.5 \%$ and destained with $10 \%$ acetic acid.

\section{Evaluation of the capacity to generate the SC5b-9 complex}

The capacity of fractions ( $\mathrm{S} 1$ to $\mathrm{S} 5$ ) to generate the SC5b-9 complex was evaluated by enzyme-linked immunosorbent assay (ELISA, Quidel SC5b-9 Complement $^{\circ}$ kit, USA) after exposure of the NHS to $50 \mu \mathrm{L}$ of each fraction [28].

\section{Statistical analysis}

The results were expressed as the mean \pm SEM. The groups were compared statistically by ANOVA followed by the Tukey post-hoc test. All data were analyzed via Prism ${ }^{\mathrm{Tw}}$ v. 5 (GraphPad Inc., USA).

\section{Results}

\section{Fractionation of $R$. schneideri poison}

The components from Rhinella schneideri poison with activity on the CS were obtained by three chromatographic steps: cation-exchange, anion-exchange and molecular exclusion. The chromatographic profile of soluble poison on CM-cellulose-52 (cation-exchange) showed seven different fractions, denominated $\mathrm{C} 1$ to C7 (Fig. 1a). Fraction C1 presents the highest inhibition of hemolytic complement activity, as previously demonstrated by our group [29]. RsP and fraction C1 were assayed by SDS-PAGE (Fig. 1b), where C1 appeared as a complex mixture of proteins. Therefore, it was submitted to the next fractionation step on a DEAE-Sepharose column (Fig. 1c).

Among the four fractions (D1, D2, D3 and D4) obtained from the rechromatography of fraction $\mathrm{C} 1$, the fraction D3 presented the highest activity on CS [29]. Unfortunately, it was composed of low- and highmolecular-mass components, highlighting a protein with an approximate molecular mass of $6 \mathrm{kDa}$, observed in the SDS-PAGE (Fig. 1d). In order to isolate some component presenting action on complement system, fraction D3 was submitted to a gel filtration on a Sephacryl-S200 column (Fig. 1e). Five fractions, designated S1 to S5, were obtained; and the active fractions S2 and S5 were analyzed by SDS-PAGE (Fig. 1f). Fraction $\mathrm{S} 2$ was composed of high-molecular-mass proteins $(40,000$ to $50,000 \mathrm{Da})$, while S5 was a protein of about $6 \mathrm{kDa}$. The recoveries of chromatographic fractions with activity on CS are shown in Table 1.

The active fractions S2 and S5 were submitted to a reversed phase FPLC using a C2C18 column (Fig. 2). S5 showed higher purity than $\mathrm{S} 2$, which presented a chromatographic profile with two major peaks, S2.1 and S2.2.

\section{Hemolytic complement assay}

All fractions obtained from the last chromatographic procedure were subjected to the hemolytic assay of the classical/lectin pathway, in which $100 \mu \mathrm{L}$ volumes of each fraction - $\mathrm{S} 1\left(\mathrm{~A}_{280} \sim 0.35\right), \mathrm{S} 2 \quad\left(\mathrm{~A}_{280} \sim 0.2\right), \mathrm{S} 3$ $\left(\mathrm{A}_{280} \sim 0.17\right), \mathrm{S} 4 \quad\left(\mathrm{Ab}_{280} \sim 0.1\right)$ and $\mathrm{S} 5\left(\mathrm{~A}_{280} \sim 0.16\right)-$ were used. The hemolytic activities of the classical/lectin pathways observed in the presence of all fractions were significantly lower than the positive control, particularly in the presence of fractions S2 and S5 (Fig. 3).

\section{Two-dimensional immunoelectrophoresis}

The 2D-IEP profile of the positive control shows two protein peaks, corresponding to $\mathrm{C} 3$ and $\mathrm{C} 3 \mathrm{~b}$, indicating the ability of zymosan to activate the complement system, leading to partial cleavage of C3 (Fig. 4a). A symmetrical peak was observed in the negative control, 


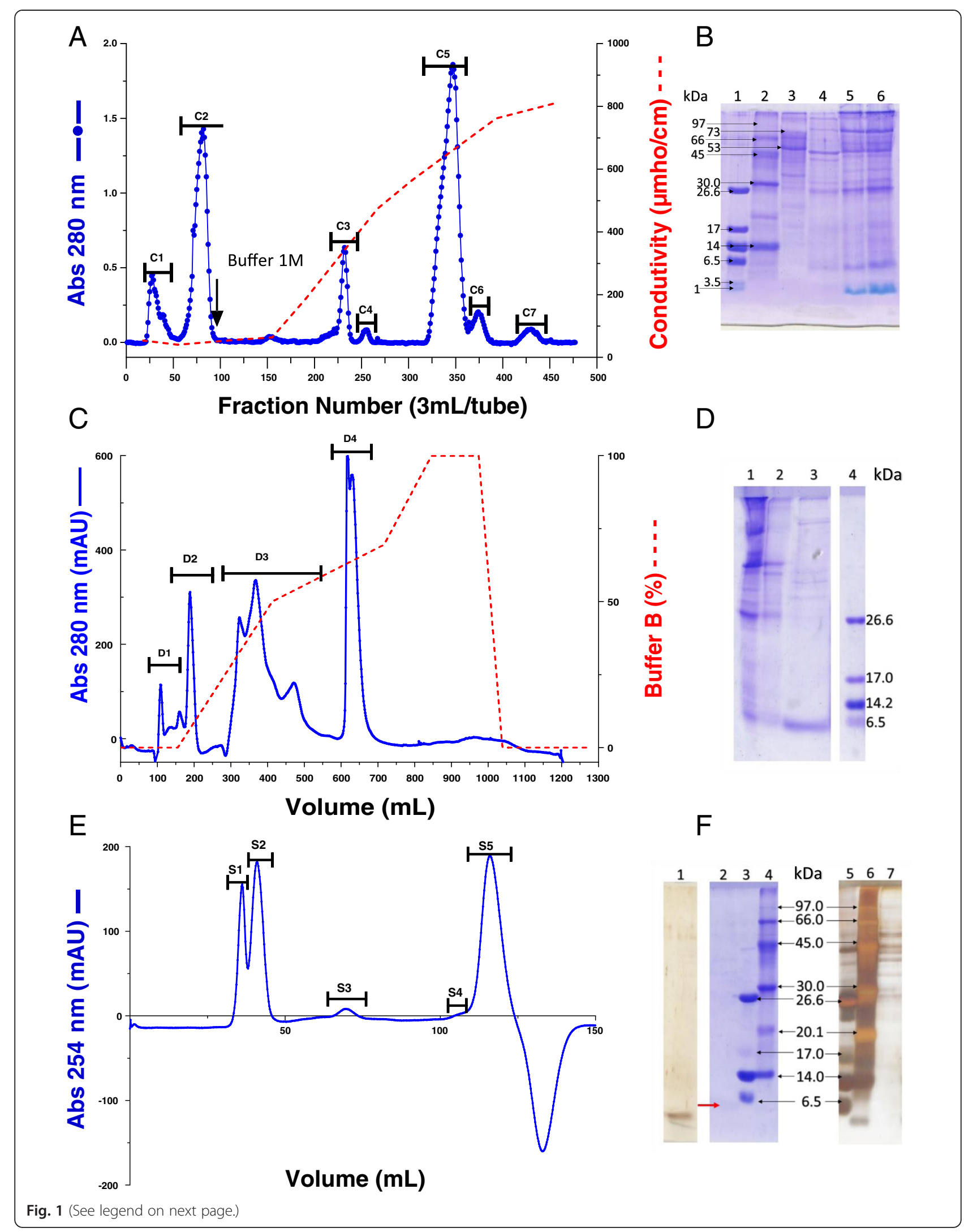


(See figure on previous page.)

Fig. 1 Fractionation of Rhinella schneideri poison (RsP). a Chromatographic profile of RsP on CM-cellulose-52. The column was equilibrated with $0.05 \mathrm{M}$ ammonium bicarbonate, $\mathrm{pH}$ 7.8. The sample (extract from $500 \mathrm{mg}$ ) was applied at a flow rate of $20 \mathrm{drops} / \mathrm{min}$; and adsorbed /components were eluted using a convex concentration gradient of $\mathrm{NH}_{4} \mathrm{HCO}_{3}(0.05$ to $1.0 \mathrm{M}$, pH 7.8). Fractions (3.0 mL/tube) were collected at $4{ }^{\circ} \mathrm{C}$. b SDS-PAGE using $13.5 \%$ separation gel. Lanes 1, 2 and 3 - ultra- mass markers, respectively. Lane 4 - fraction C1; lanes 5 and 6 - RsP. c Chromatographic low (Sigma-Aldrich, USA), low-high (GE Healthcare, Sweden) and high (GE Healthcare, Sweden) molecular profile of fraction C1 on DEAE-Sepharose. The column was equilibrated with $0.05 \mathrm{M} \mathrm{Tris-HCl,} \mathrm{pH} 7.8$ (buffer A). The sample (56.6 $\mathrm{mg}$ of (1) was applied at a flow rate of $0.5 \mathrm{~mL} / \mathrm{min}$; and adsorbed components were eluted using a linear gradient from 0-1 M $\mathrm{NaCl}$ in equilibrating buffer (buffer B). Elution with $100 \%$ buffer B was achieved after $150 \mathrm{~mL}$. d SDS-PAGE using $13.5 \%$ separation gel. Lane 1 - RsP; lane 2 - fraction C1; lane 3 - fraction D3; lane 4 - ultra-low molecular mass markers (Sigma-Aldrich, USA). e Chromatographic profile of fraction D3 on Sephacryl S-200. The column, equilibrated with PBS, pH 7.4, was eluted with this same buffer (flow rate: $0.4 \mathrm{~mL} / \mathrm{min}$ ) and fractions of $1 \mathrm{~mL}$ were collected. In (a) and (c), the elution profiles were monitored at $280 \mathrm{~nm}$, while in (e) the profile was monitored at 254 nm. f SDS-PAGE using $13.5 \%$ separation gel. Lanes 1 and 2 - fraction S5; lanes 3 and 5 - ultra-low-molecular-mass markers (Sigma-Aldrich, USA); lanes 4 and 6 - low-molecular-mass markers (GE Healthcare, Sweden); lane 7 - fraction S2

corresponding to intact $\mathrm{C} 3$. The 2D-IEP profiles obtained in the presence of S2 and S5 (Fig. 4b and c, respectively) also showed two peaks, similar to the positive control, corresponding to $\mathrm{C} 3$ and $\mathrm{C} 3 \mathrm{~b}$, indicating that $\mathrm{S} 2$ and S5 were able to activate the complement system. The background of these 2D-IEP profiles (Fig. 4a, b and c) were removed in order to highlight the presence of one peak for negative control and two peaks for positive control, S2 and S5 assays (Fig. 4d).

\section{Neutrophil chemotaxis assay}

A significant $(p<0.001)$ increase in neutrophil migration was observed by preincubation of poison components S2 and S5 with NHS (Fig. 5). These results indicate that S2 and S5 were able to induce activation of the complement system, leading to the formation of chemotactic factors.

\section{Evaluation of the capacity to generate the SC5b-9 complex}

The concentrations of SC5b-9 complex produced after exposure to NHS with fractions S1, S2, S3, S4 and S5, as well as zymosan (positive control) were determined by enzyme-linked immunosorbent assay (Fig. 6). S2 showed significant capacity to generate the SC5b-9 complex compared to the negative control $(p<0.01)$ and $\mathbb{S}$ compared to $\mathrm{S} 4(p<0.05)$.

\section{Discussion}

Research involving animal-derived substances that act on the complement system has been well documented

Table 1 Recovery of the chromatographic components obtained during the fractionation procedure

\begin{tabular}{lll}
\hline Fraction & Fractionation step & Fraction recovery $^{\mathrm{a}}(\%)$ \\
\hline RsP & --- & 100.0 \\
C1 & CM-cellulose-52 & 7.6 \\
D3 & DEAE-Sepharose & 4.1 \\
S2 and S5 & Sephacryl-S100 & $1.2($ S2) and 2.1(S5) \\
\hline
\end{tabular}

${ }^{\mathrm{a}}$ Total recovery was calculated based on the area under the peak by UNICORN software (GE Healthcare, Sweden) in the literature. Spider (Loxosceles), snake (Elapidae, Crotalidae and Viperidae), honeybee, wasp and scorpion venoms have demonstrated the ability to activate the CS [30-35]. This activation can be initiated by cleavage of a specific component or by interaction with other CS components resulting in the formation of the "membrane attack complex" [32]. Tityus serrulatus venom activates the CS, leading to factor B and C3 cleavage, reduction of serum lytic activity and generation of complement chemotactic factors [30]. Assis et al. [16] showed that fractionation of the poisonous secretion of $B$. marinus paracnemis Lutz (currently named Rhinella schneideri), by dialysis and chromatography on QAE-Sephadex, yielded a fraction with anticomplementary activity when incubated with human serum. This effect was evaluated by measuring the kinetics of lytic activity on sensitized sheep red blood cells (classical pathway) and unsensitized rabbit cells (alternative pathway). A study of the skin secretion of six species of common toads in China revealed that only Bombina maximum poison showed direct hemolytic activity at a dose of $20 \mu \mathrm{g} / \mathrm{mL}$ [36].

This study describes the effects of two components from RsP that interfere with CP/LP of the complement system. To the best of our knowledge, only one study reported the interaction of RsP with the CS until now [16]. The ability of this poison to induce serum-related leukocyte recruitment was evaluated as an indicator of complement activation and consequent generation of complement chemotactic factors.

The procedure used in this study to fractionate the active compound from RsP was relatively simple, involving only three chromatographic steps, a cationic and an anionic chromatography followed by a gel filtration. The SDSPAGE results show that fraction $\mathrm{C} 1$, active on $\mathrm{CS}$, is composed of high- and low-molecular-mass proteins. The major protein of fraction D3 has a molecular mass of about $60,000 \mathrm{Da}$ and corresponds to the isolated S5 active component. On the other hand, the fraction S2 is composed mainly of high-molecular-weight proteins $(40,000-$ $50,000 \mathrm{Da})$. The chromatographic profile of the RP-FPLC S5 confirms the high purity of this component. 


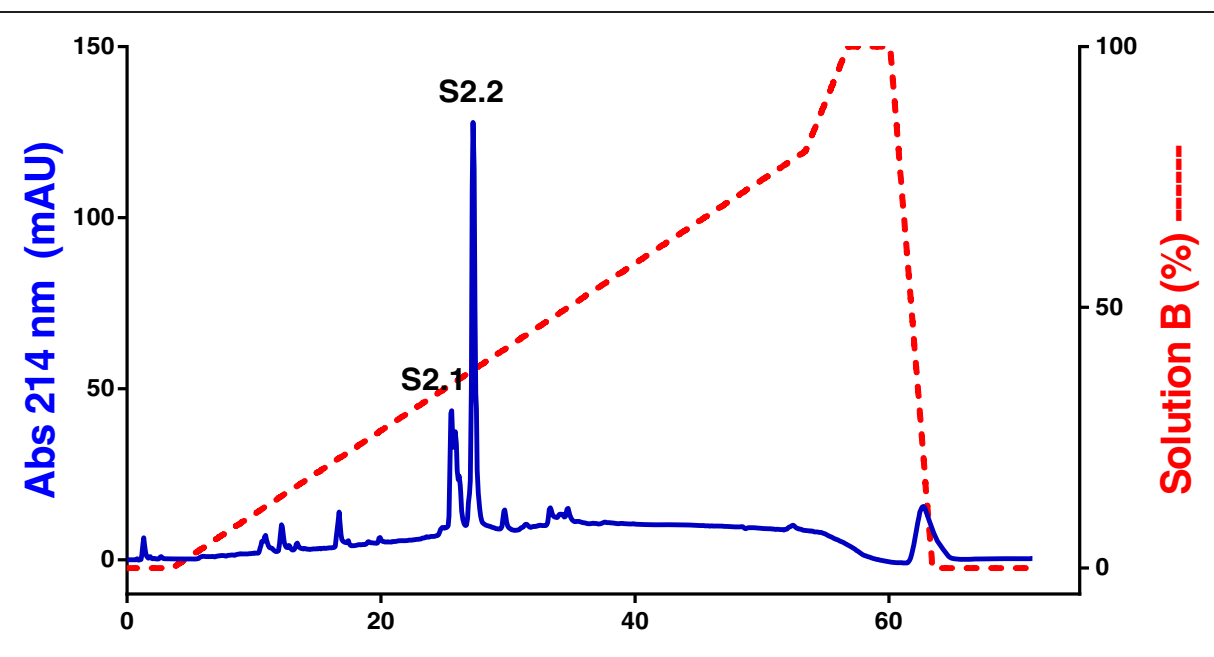

\section{Volume $(\mathrm{mL})$}

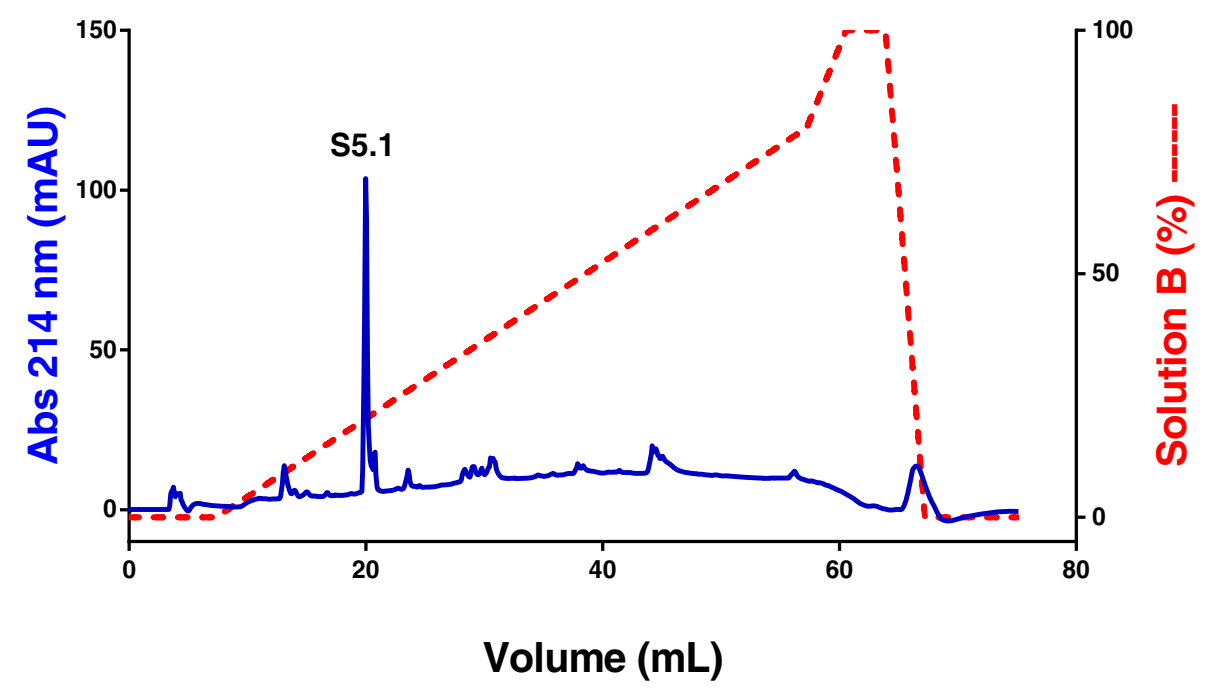

Fig. 2 Reversed-phase FPLC of fractions S2 and S5. The C2C18 column was equilibrated with $0.1 \%$ (VN) trifluoroacetic acid (TFA, solution A). Adsorbed proteins were eluted using a concentration gradient from 0 to $100 \%$ of solution B ( $80 \%$ acetonitrile in $0.1 \%$ TFA, VN). Fractions of $0.5 \mathrm{~mL} /$ tube were collected at a flow rate of $0.5 \mathrm{~mL} / \mathrm{min}$

The complement activation occurs along classical, alternative or lectin pathways leading to a cascade of component interactions and generation of products that present such biological activities as anaphylaxis, chemotaxis, opsonization, immune complex solubilization, participation in the immune response and other activities [17-19]. Two important mediators of the inflammatory reaction, $\mathrm{C} 3 \mathrm{a}$ and $\mathrm{C} 5 \mathrm{a}$, are produced as a consequence of CS activation [17-19].

The hemolytic complement assay was used to ensure the functional integrity of the whole pathways (classical or alternative) with the terminal pathway. The results obtained showed that all fractions $\left(\mathrm{S} 1-\mathrm{A}_{280} \sim 0.35, \mathrm{~S} 2-\right.$ $\mathrm{A}_{280} \sim 0.2, \mathrm{~S} 3-\mathrm{A}_{280} \sim 0.17, \mathrm{~S} 4-\mathrm{Ab}_{280} \sim 0.1$ and $\mathrm{S} 5-$ $\left.\mathrm{A}_{280} \sim 0.16\right)$ induced significant reductions in hemolytic activity of classical/lectin pathways, but smaller hemolysis values were obtained in the presence of S2 and S5 $(p<$ 0.0001). The solutions of the fractions (S1-S5) used in the hemolytic assay showed different absorptions at $280 \mathrm{~nm}$. Contrary to what might be expected in this context, our objective was to perform only a qualitative analysis of the effect of the fractions on the CS. The fraction solutions with the highest possible concentration were used, considering their solubility as well as the amount obtained from each fraction (S3 and $\mathrm{S} 4$ are present in low proportion in the fraction D3 - Fig. 1e).

We have chosen to use the absorbance at $280 \mathrm{~nm}$ and the volume as a means to quantify the samples, because toad poison is composed of proteic (protein and peptides) and non-proteic (mucus, biogenic amines, steroids 


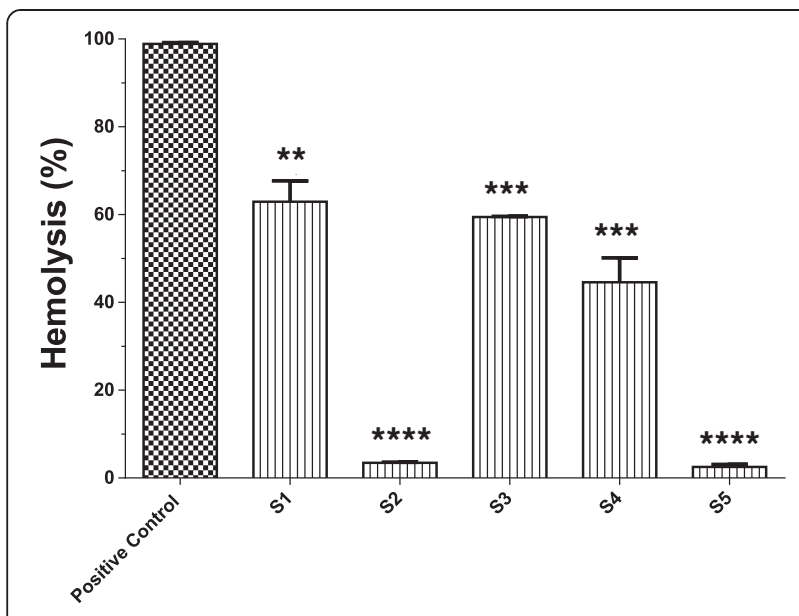

Fig. 3 Effect of fractions S1 - S5 on the classical/lectin hemolytic pathways of complement activation. The fractions $(100 \mu \mathrm{L}$ in PBS, $\mathrm{S} 1-\mathrm{A}_{280} \sim 0.35 ; \mathrm{S} 2-\mathrm{A}_{280} \sim 0.20 ; \mathrm{S} 3-\mathrm{A}_{280} \sim 0.17 ; \mathrm{S} 4-\mathrm{A}_{280} \sim 0.10$ and $\left.\left.S 5-A_{280} \sim 0.16\right)\right)$ were incubated for one hour at $37^{\circ} \mathrm{C}$ with normal human serum diluted 1:20 (37.5 $\mu \mathrm{L})$ and CFD/Gel solution $(12.5 \mu \mathrm{L})$. The positive control was run under the same conditions but in the absence of fractions. The absorbances of supernatants from cells incubated in CFD/Gel buffer (0 \% lysis) and lysed in water (100 \% lysis) were employed to calculate the percentage of lysis induced by NHS in the absence (positive control) or presence of the fractions (tests). The columns represent means \pm SEM of an experiment performed in duplicate. ${ }^{* *} p<0.01,{ }^{* * *} p<0.001$ and **** $p<0.0001$ compared to the positive control

and alkaloids) compounds. The non-proteic compounds interfere with many protein quantification assays, invalidating the measurement of the sample. According to Marongio [29], the protein concentration, determined by the biuret method, of a dispersion of $5 \mathrm{mg} / \mathrm{mL}$ of the $R$. schneideri poison was only $1.32 \mathrm{mg} / \mathrm{mL}$, corresponding to $26 \%$ of the total weight of the poison.

The reduction in CP/LP lytic activity induced by S2 and S5 suggests an activation of the complement cascade during the preincubation phase (NHS + fractions) and subsequent inactivation (unstable components). The CS activation preceding the addition of red blood cells would reduce serum concentrations of complement components, thereby leading to decreased NHS lytic activity during the hemolytic assay. Similar results were observed in studies of snake venoms from the genera Bothrops (B. jararaca, B. moojeni and B. cotiara), Micrurus (M. ibiboboca and M. spixii) and Naja (N. naja, N. melanoleuca and N. nigricollis) [32, 37, 38].

The presence of an inhibitor of CS in RsP is also possible, since protease inhibitors have been identified on the skin of Anura species [39-41]. Several compounds can modify or interact with CS by activating or inhibiting it [16, 30-38, 42]. Peptides synthesized from phage-displayed peptide libraries based on $\mathrm{C} 1 \mathrm{q}$ binding are able to inhibit the hemolytic activity of the classical complement pathway [43]. Another peptide from phage-displayed libraries, the compstatin peptide, a 13 -amino-acid cyclic peptide, binds to a $\beta$-chain of $\mathrm{C} 3$ and inhibits activation of both the classical and alternative pathways $[44,45]$.

The immunoelectrophoresis assay showed that cleavage of C3 in serum incubated with S2 and S5 (Fig. 4b and c, respectively), was similar to that induced by incubation of NHS with zymosan (positive control, Fig. 4a), corroborating the hypothesis that poison components induce activation of the CS. Bertazzi et al. [30] showed that Tityus serrulatus venom was also able to alter C3 immunoelectrophoresis migration after incubation with NHS.

The chemotaxis assay served as an indicator of the activation of CS and consequent generation of neutrophil chemoattractant factors. S2 and S5 increased neutrophil migration by interacting with CS components, leading to subsequent cleavage of $\mathrm{C} 3$ and $\mathrm{C} 5$, which produced the active fragments $\mathrm{C} 3 \mathrm{a}$ and $\mathrm{C} 5 \mathrm{a}$ (anaphylatoxins) during the preincubation phase $\left(60 \mathrm{~min}\right.$ at $\left.37^{\circ} \mathrm{C}\right)$ of NHS with fractions. These results were similar to that presented by zymosan (positive control) and confirm that S2 and S5 are able to activate the complement system. A similar effect was observed in a prior study on Tityus serrulatus venom [30]. BaP1, a $24 \mathrm{kDa}$ metalloprotease isolated from Bothrops asper venom, induced neutrophil chemotaxis that was mediated by agents derived from activation of the complement system $[37,46]$.

The assay performed to evaluate the capacity of the Rs $\mathrm{P}$ components to induce SC5b-9 complex formation showed that only $\mathrm{S} 2$ was able to induce a significant increase $(p<0.01)$ in the SC5b-9 concentration, compared to negative control (Fig. 6). This assay was conducted to better clarify the action of fractions on the complement system and provided an additional indication of the terminal complement system activation induced by $\mathrm{S} 2$.

Primary among the effects of SC5b-9 complex is tissue injury through cell lysis or stimulation of pro-inflammatory mediators [47]. It is known that more than $80 \%$ of C5a and SC5b-9 is generated by activation of the mannosebinding lectin or classical pathway [48, 49]. High levels of activation and generation of SC5b-9 complex are related to several pathological states, including lupus erythematosus and rheumatoid arthritis [47].

Proteolytic activity evaluation of the fractions S2 and S5 was performed using chromogenic substrate for alpha-chymotrypsin (Sigma-S7388, N-Succinyl-Ala-AlaPro-Phe p-nitroanilide, Sigma-Aldrich, USA) and for coagulation proteases [Sigma-T6140, N-(p-Tosyl)-GlyPro-Lys 4-nitroanilide acetate salt, Sigma-Aldrich, USA]. Additionally, these fractions were subjected to assays to evaluate inhibitory activity against trypsin and chymotrypsin proteases. Neither fraction showed proteolytic or inhibitory activity (data not shown), indicating that their 


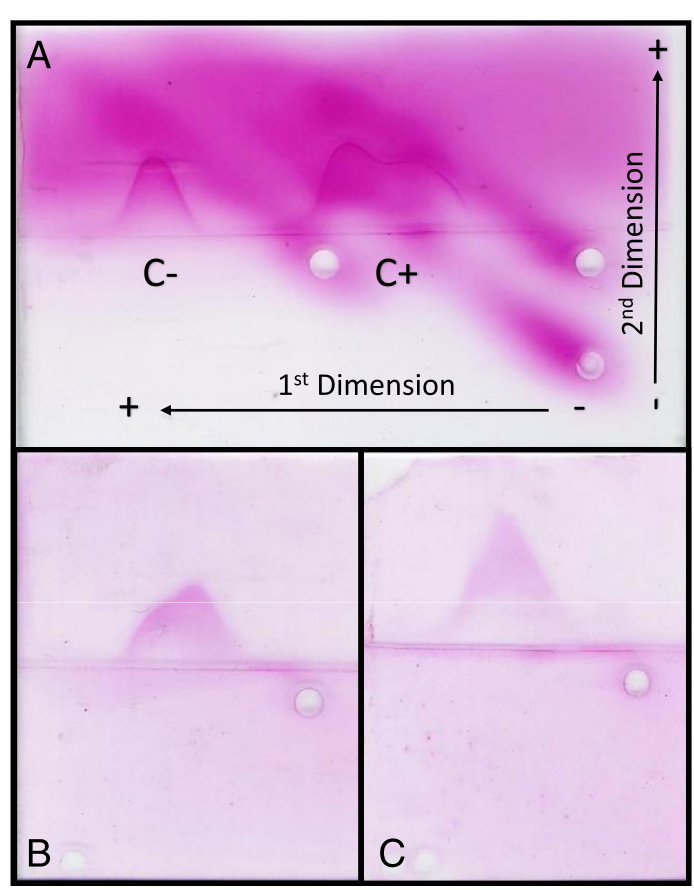

Fig. 4 Immunoelectrophoretic analysis of C3 in NHS incubated with fractions S2 and S5. a Positive control (C+) with zymosan (31.25 $\mu \mathrm{L}, 1 \mathrm{mg} / \mathrm{mL})$

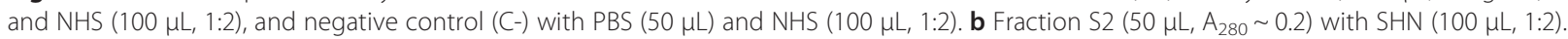
c Fraction S5 $\left(50 \mu \mathrm{L}, \mathrm{A}_{280} \sim 0.16\right)$ with NHS $(100 \mu \mathrm{L}, 1: 2)$. All mixtures were incubated for 60 min in a water bath at $37^{\circ} \mathrm{C}$. The plates were dried at room temperature, stained with $0.5 \%$ Ponceau and bleached with $10 \%$ acetic acid. Electrophoretic conditions: first dimension - four hours, $140 \mathrm{~V}$ at $15 \mathrm{~mA}$ and $10 \mathrm{~W}$; second dimension $-14 \mathrm{~h}$ at $15 \mathrm{~mA}$ and $10 \mathrm{~W}$. d Figures were manipulated to remove the background highlighting the presence of one peak for $\mathrm{C}$ - and two peaks for $\mathrm{C}+, \mathrm{S} 2$ and $\mathrm{S} 5$ assays

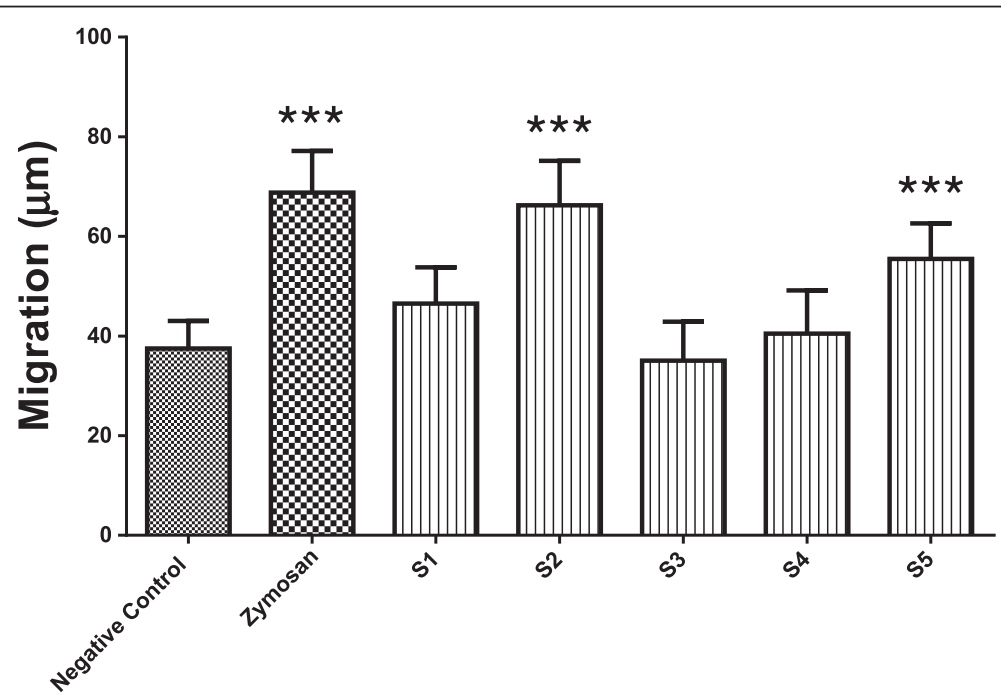

Fig. 5 Neutrophil chemotaxis induced by normal human serum (NHS) preincubated with fractions S1 - S5. The fractions were preincubated with NHS for $60 \mathrm{~min}$ at $37^{\circ} \mathrm{C}$. The positive control consisted of $120 \mu \mathrm{L}$ of NHS with $100 \mu \mathrm{L}$ of CFD/Gel buffer and $75 \mu \mathrm{L}$ of zymosan ( $\left.1 \mathrm{mg} / \mathrm{mL}\right)$, while the negative control was $120 \mu \mathrm{L}$ of NHS with $100 \mu \mathrm{L}$ of CFD/Gel buffer. Neutrophil migration was assessed by the leading-front technique, in which at least ten microscopic fields were analyzed per filter at 100x magnification. The columns represent the means \pm SEM of one experiment done in triplicate. ${ }^{* *} p<0.001$ compared to the negative control 


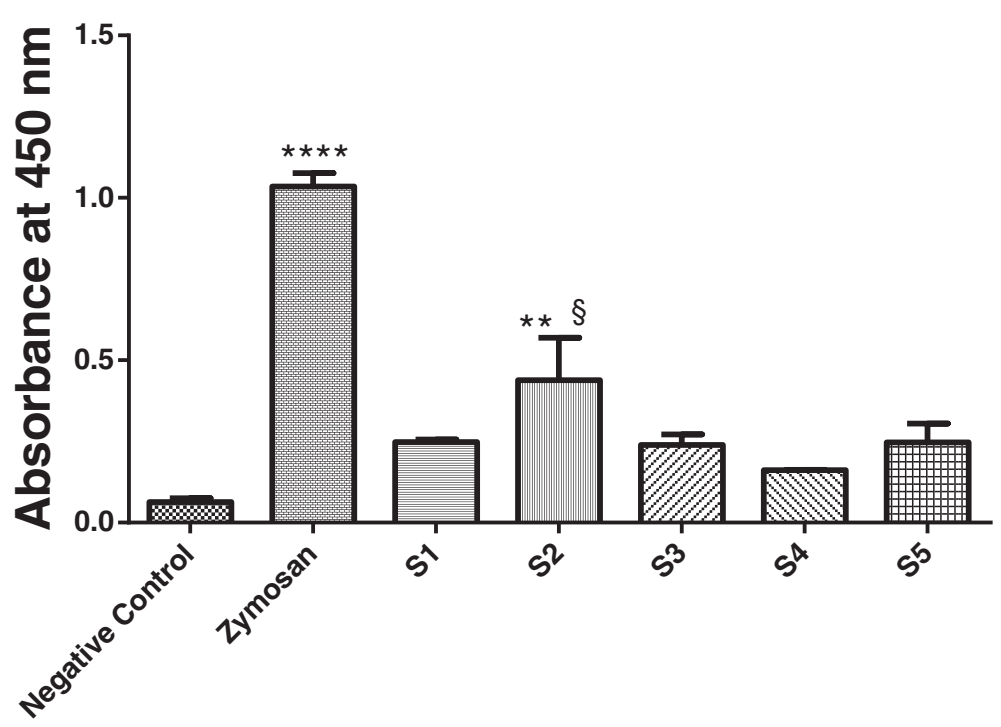

Fig. 6 Formation of the SC5b-9 complex. NHS was incubated for 60 min with PBS (negative control), zymosan (positive control; $1 \mathrm{mg} / \mathrm{mL}$ ) and fractions S1 to S5. The assay was done using a commercial kit (Quidel SC5b-9 Complement ${ }^{\oplus}$ kit, USA). The columns represent the means \pm SEM of one experiment done in duplicate. ${ }^{* *} p<0.01$ and ${ }^{* * *} p<0.0001$ compared to the negative control, and $\S p<0.05$ compared to $\$ 4$

actions on the CS are not by proteolysis or inhibition of the complement cascade proteases.

Several approaches are being proposed for the development of new pharmacological agents directed at diseases in which the CS is active [47, 50-53]. Cobra venom factor (CVF) is a non-toxic venom compound with functional and structural characteristics very similar to the complement component $\mathrm{C} 3[53,54]$. The development of the humanized version of CVF is a promising therapeutic agent for many pathologies [50, 52, 53].

\section{Conclusion}

In summary, our results indicate that $R s \mathrm{P}$ presents components, especially $\mathrm{S} 2$ and $\mathrm{S} 5$, that are able to activate the complement cascade, as evidenced by the decreased serum lytic activity, production of C3 fragments, increased leukocyte migration and SC5b-9 generation. Based on these findings, the RsP may be considered a rich source of substances that can be used as molecular tools to study dysfunction of the CS, since they are able to modulate the activity of this system.

\section{Ethics committee approval}

All experiments were approved and conducted in accordance with the ethical principles in animal experimentation adopted by the Ethics Commission for the Use of Animals (CEUA), Campus of Ribeirão Preto, USP (protocol $\mathrm{n}^{\circ}$ 05.1.637.53.6). The use of human blood was approved by the Research Ethics Committee of the School of Pharmaceutical Sciences of Ribeirão Preto, University of São Paulo (USP) under protocol $\mathrm{n}^{\circ}$ 0022.0.212.000-08.

\section{Abbreviations}

AP: Alternative pathway; CFD: Complement fixation diluents; CP/LP: Classical/ lectin pathway; CVF: Cobra venom factor; FPLC: Fast protein liquid chromatography; Gel: Gelatin; CS: Complement system; 2D-IEP: Twodimensional immunoelectrophoresis; MAC or SC5b-9: Membrane attack complex; NHS: Normal human serum; PBS: Phosphate-buffered saline; RsP: Rhinella schneideri poison; SDS-PAGE: Sodium dodecyl sulfate polyacrylamide gel electrophoresis; TFA: Trifluoroacetic acid.

\section{Competing interests}

The authors declare that they have no competing interests.

\section{Authors' contributions}

FAPA conducted the experiments, performed data analysis and wrote the manuscript. FPL, AECSA and JCP assisted in the experiments. KCFB assisted in the experiments and contributed to the writing of the manuscript. LSPC participated in the research design and contributed to the writing of the manuscript. ECA is the corresponding author and also participated in the research design and contributed to the writing of the manuscript. All authors read and approved the final manuscript.

\section{Acknowledgments}

The authors are grateful to the National Council for Scientific and Technological Development (CNPq), the State of São Paulo Research Foundation (FAPESP scholarship to FAPA, n. 2008/56327-0) and the Coordination for the Improvement of Higher Education Personnel (CAPES - scholarship to FAPA) and the Support Nucleus for Research on Animal Toxins (NAP-TOXAN-USP, grant n. 12-125432.1.3) for financial support. The authors also acknowledge the biologist Luiz Henrique Anzaloni Pedrosa for extracting the toad venom. Thanks are also due to the Center for the Study of Venoms and Venomous Animals (CEVAP) of UNESP for enabling the publication of this special collection (CNPq process 469660/2014-7).

\section{Author details}

'Department of Physics and Chemistry, School of Pharmaceutical Sciences of Ribeirão Preto, University of São Paulo (USP), Avenida do Café, s/n, Ribeirão Preto 14.040-903 SP, Brazil. ²Department of Clinical Analyses, Toxicology and Food Sciences, School of Pharmaceutical Sciences of Ribeirão Preto, University of São Paulo (USP), Avenida do Café, s/n, Ribeirão Preto 14.040-903 SP, Brazil.

Received: 1 December 2014 Accepted: 21 July 2015

Published online: 13 August 2015 


\section{References}

1. AmphibiaWeb. Information on amphibian biology and conservation. Species Numbers, 2000. http://www.amphibiaweb.org/amphibian/speciesnums.html. Accessed 13 Nov 2014.

2. Frost D. Amphibian species of the world 6.0, an online reference. http:// research.amnh.org/herpetology/amphibia/index.html. Accessed 10 Nov 2014

3. Maciel NM, Collevatti RG, Colli GR, Schwartz EF. Late Miocene diversification and phylogenetic relationships of the huge toads in the Rhinella marina (Linnaeus, 1758) species group (Anura: Bufonidae). Mol Phylogenet Evol. 2010;57(2):787-97.

4. Clarke BT. The natural history of amphibian skin secretions, their normal functioning and potential medical applications. Biol Rev Camb Philos Soc. 1997;72(3):365-79

5. Sakate M. Lucas de Oliveira PC. Toad envenoming in dogs: effects and treatment. J Venom Anim Toxins. 2000;6(1):52-62.

6. Toledo RC, Jared C. Cutaneous granular glands and amphibian venoms. Comp Biochem Phys A. 1995;111(1):1-29.

7. Lee S, Lee Y, Choi YJ, Han KS, Chung HW. Cyto-/genotoxic effects of the ethano extract of Chan Su, a traditional chinese medicine, in human cancer cell lines. J Ethnopharmacol. 2014;152(2):372-6.

8. Chow L, Johnson M, Wells A, Dasgupta A. Effect of the traditional Chinese medicines Chan Su, Lu-Shen-Wan, Dan Shen, and Asian ginseng on serum digoxin measurement by Tina-quant (Roche) and Synchron LX system (Beckman) digoxin immunoassays. J Clin Lab Anal. 2003;17(1):22-7.

9. Chen KK, Koraríková A. Pharmacology and toxicology of toad venom. J Pharm Sci. 1967;56(12):1535-41.

10. Gomes A, Giri B, Alam A, Mukherjee S, Bhattacharjee P, Gomes A. Anticancer activity of a low immunogenic protein toxin (BMP1) from Indian toad (Bufo melanostictus, Schneider) skin extract. Toxicon. 2011;58(1):85-92.

11. Zhang L, Nakaya K, Yoshida T, Kuroiwa Y. Induction by bufalin of differentiation of human leukemia cells HL60, U937, and ML1 toward macrophage/monocyte-like cells and its potent synergistic effect on the differentiation of human leukemia cells in combination with other inducers. Cancer Res. 1992;52(17):4634-41.

12. Zuo-Qing L. Traditional Chinese medicine for primary liver cancer. World J Gastroenterol. 1998:4(4):360-4.

13. Yeh JY, Huang WJ, Kan SF, Wang PS. Effects of bufalin and cinobufagin on the proliferation of androgen dependent and independent prostate cancer cells. Prostate. 2003;54(2):112-24

14. Shen S, Zhang Y, Wang Z, Liu R, Gong X. Bufalin induces the interplay between apoptosis and autophagy in glioma cells through endoplasmic reticulum stress. Int J Biol Sci. 2014;10(2):212-24.

15. Jiang L, Zhao MN, Liu TY, Wu XS, Weng H, Ding Q, et al. Bufalin induces cell cycle arrest and apoptosis in gallbladder carcinoma cells. Tumour Biol. 2014;35(11):10931-41.

16. Assis Al, Barbosa JE, Carvalho IF. Anticomplementary fraction from the poisonous secretion of paratoid gland of the toad (Bufo marinus paracnemis Lutz). Experientia. 1985;41(7):940-2.

17. Janeway CA, Travers P, Walport M, Shlomchik MJ. O sistema complemento e a imunidade inata. In: Janeway Junior CA, Shlomchik MJ, Travers P, Walport M, editors. Imunobiologia: o sistema imune na saúde e na doença. 5th ed. Porto Alegre: Artmed; 2002. p. 63-83.

18. Sarma JV, Ward PA. The complement system. Cell Tissue Res. 2011;343(1):227-35.

19. Ricklin D, Hajishengallis G, Yang K, Lambris JD. Complement: a key system for immune surveillance and homeostasis. Nat Immunol. 2010;11(9):785-97.

20. Arantes EC, Prado WA, Sampaio SV, Giglio JR. A simplified procedure for the fractionation of Tityus serrulatus venom: isolation and partial characterization of TsTX-IV, a new neurotoxin. Toxicon. 1989;27(8):907-16.

21. Laemmli UK. Cleavage of structural protein during the assembly of the head of bacteriophage T4. Nature. 1970;227(5259):680-5

22. Harrison RA, Lachmann PJ. Complement technology. In: Weir DM, editor. Handbook of experimental immunology. Oxford, UK: Blackwell Scientific Publications; 1986. p. 39.1-39.49.

23. Hoffmann LG, Mayer MM. Immune hemolysis and complement fixation. In: Williams CA, Chase MW, editors. Methods in immunology and immunochemistry. New York: Academic; 1977. p. 140.

24. Paula FS, Kabeya LM, Kanashiro A, de Figueiredo AS, Azzolini AE, Uyemura AS, et al. Modulation of human neutrophil oxidative metabolism and degranulation by extract of Tamarindus indica $L$. fruit pulp. Food Chem Toxicol. 2009;47(1):163-70.
25. Boyden S. The chemotactic effect of mixtures of antibody and antigen on polymorphonuclear leukocytes. J Exp Med. 1962;115:453-66.

26. Zigmond $\mathrm{SH}$, Hirsch JG. Leukocyte locomotion and chemotaxis: new methods for evaluation, and demonstration of a cell-derived chemotactic factor. J Exp Med. 1973;137(2):387-410.

27. Clarke HG, Freeman T. Quantitative immunoelectrophoresis of human serum proteins. Clin Sci. 1968;35(2):403-13.

28. Deppisch R, Schmitt V, Bommer J, Hänsch GM, Ritz E, Rauterberg EW. Fluid phase generation of terminal complement complex as a novel index of bioincompatibility. Kidney Int. 1990;37(2):696-706.

29. Marongio AFQ. Isolamento e caracterização parcial do componente do veneno de Bufo paracnemis com ação sobre o sistema complemento. Estudos in vitro e atividade proteolítica. MSs Thesis. São Paulo: Faculdade de Ciências Farmacêuticas de Ribeirão Preto - USP; 2006.

30. Bertazzi DT, de Assis-Pandochi Al, Talhaferro VL. Caleiro Seixas Azzolini AE, Pereira Crott LS, Arantes EC. Activation of the complement system and leukocyte recruitment by Tityus serrulatus scorpion venom. Int Immunopharmacol. 2005;5(6):1077-84.

31. Bertazzi DT, de Assis-Pandochi Al, Azzolini AE, Talhaferro VL, Lazzarini M, Arantes EC. Effect of Tityus serrulatus scorpion venom and its major toxin TsTX-I, on the complement system in vivo. Toxicon. 2003:41(4):501-8.

32. Farsky SH, Gonçalves LR, Gutíerrez JM, Correa AP, Rucavado A, Gasque P, et al. Bothrops asper snake venom and its metalloproteinase BaP-1 activate the complement system. Role in leucocyte recruitment. Mediators Inflamm. 2000;9(5):213-21.

33. Silva WDD, Tambourgi DV, Campos ACMR, Magnoli F, Petricevich VL, Kipnis TL. Complement activation by animal venoms. Toxin Rev. 1995;14(3):375-400.

34. Gebel HM, Finke JH, Elgert KD, Campbell BJ, Barret JT. Inactivation of complement by Loxosceles reclusa spider venom. Am J Trop Med Hyg. 1979:28(4):756-62.

35. Tanaka GD, Pidde-Queiroz G, Furtado MFD, van den Berg C, Tambourgi DV Micrurus snake venoms activate human complement system and generate anaphylatoxins. BMC Immunol. 2012;13:4.

36. Lai R, Zhao Y, Yang D-M, Zha H, Lee W, Zhang Y. Comparative study of the biological activities of the skin secretions from six common Chinese amphibians. Zool Res. 2000;23(2):113-9.

37. Farsky SH, Walber J, Costa-Cruz M, Cury Y, Teixeira CF. Leukocyte response induced by Bothrops jararaca crude venom: in vivo and in vitro studies. Toxicon. 1997:35(2):185-93.

38. Tambourgi DV, Dos Santos MC, Furtado MFD, de Freitas MCW, da Silva WD, Kipnis TL. Pro-inflammatory activities in elapid snake venoms. $\mathrm{Br} J$ Pharmacol. 1994;112(3):723-7.

39. Chen T, Shaw C. Identification and molecular cloning of novel trypsin inhibitor analogs from the dermal venom of the Oriental fire-bellied toad (Bombina orientalis) and the European yellow-bellied toad (Bombina variegata). Peptides. 2003;24(6):873-80

40. Conlon JM, Kim JB. A protease inhibitor of the Kunitz family from skin secretions of the tomato frog, Dyscophus guineti (Microhylidae). Biochem Biophys Res Commun. 2000;279(3):961-4.

41. Mignogna G, Pascarella S, Wechselberger C, Hinterleitner C, Mollay C, Amiconi G, et al. BSTI, a trypsin inhibitor from skin secretions of Bombina bombina related to protease inhibitors of nematodes. Protein Sci. 1996;5(2):357-62

42. Chakrabarty AK, Saha K, Sen P, Sharma KK, Agarwal SK. Effects of antibacterial agents on the complement system. Immunopharmacology. 1981;3(4):281-7.

43. Roos A, Nauta AJ, Broers D, Faber-Krol MC, Trouw LA, Drijfhout JW, et al. Specific inhibition of the classical complement pathway by C1q-binding peptides. J Immunol. 2001;167(12):7052-9.

44. Furlong S, Dutta A, Coath M, Gormley J, Hubbs S, Lloyd D, et al. C3 activation is inhibited by analogs of compstatin but not by serine protease inhibitors or peptidyl alpha-ketoheterocycles. Immunopharmacology. 2000;48(2):199-212.

45. Soulika AM, Holland MC, Sfyroera G, Sahu A, Lambris JD. Compstatin inhibits complement activation by binding to the beta-chain of complement factor 3. Mol Immunol. 2006;43(12):2023-9.

46. Gutiérrez JM, Romero M, Diaz C, Borkow G, Ovadia M. Isolation and characterization of a metalloproteinase with weak hemorrhagic activity from the venom of the snake Bothrops asper (terciopelo). Toxicon. 1995;33(1):19-29.

47. Rus V, Malide D, Bolosiu HD, Parasca I, Dutu AL. Levels of SC5b-9 complement complex in plasma and synovial fluid of patients with rheumatic disease. Med Interne. 1990;28(4):305-10. 
48. Harboe M, Ulvund G, Vien L, Fung M, Mollnes TE. The quantitative role of alternative pathway amplification in classical pathway induced terminal complement activation. Clin Exp Immunol. 2004;138(3):439-46.

49. Harboe M, Garred P, Karlstrom E, Lindstad JK, Stahl GL, Mollnes TE. The down-stream effects of mannan-induced lectin complement pathway activation depend quantitatively on alternative pathway amplification. Mol Immunol. 2009;47(2-3):373-80.

50. Vogel CW, Finnegan PW, Fritzinger DC. Humanized cobra venom factor: structure, activity, and therapeutic efficacy in preclinical disease models. Mol Immunol. 2014;61(2):191-203.

51. Mao YF, Yu QH, Zheng XF, Liu K, Liang WQ, Wang YW, et al. Pre-treatment with Cobra venom factor alleviates acute lung injury induced by intestinal ischemia-reperfusion in rats. Eur Rev Med Pharmacol Sci. 2013;17(16):2207-17.

52. Vogel CW, Fritzinger DC, Gorsuch WB, Stahl GL. Complement depletion with humanised cobra venom factor: efficacy in preclinical models of vascular diseases. Thromb Haemost. 2015;113(3):548-52.

53. Vogel CW, Fritzinger DC. Cobra venom factor: structure, function, and humanization for therapeutic complement depletion. Toxicon. 2010;56(7):1198-222.

54. Vogel CW, Fritzinger DC, Hew BE, Thorne M, Bammert H. Recombinant cobra venom factor. Mol Immunol. 2004:41(2-3):191-9.

\section{Submit your next manuscript to BioMed Central and take full advantage of:}

- Convenient online submission

- Thorough peer review

- No space constraints or color figure charges

- Immediate publication on acceptance

- Inclusion in PubMed, CAS, Scopus and Google Scholar

- Research which is freely available for redistribution 